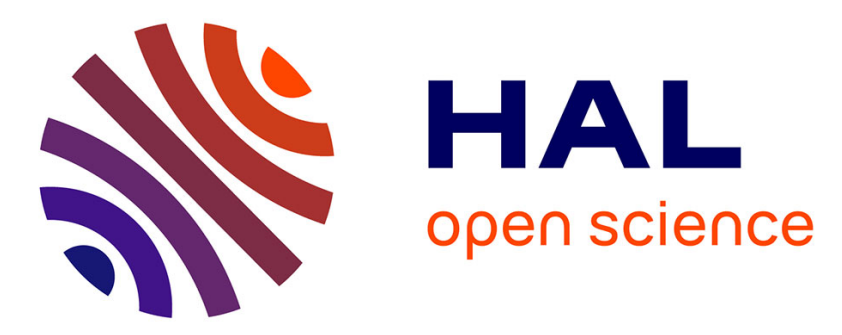

\title{
The influence of birth date via body mass on individual fitness in a long-lived mammal
}

F. Plard, J. M. Gaillard, T. Coulson, A. J. Hewison, M. Douhard, F. Klein, D. Delorme, C. Warnant, C. Bonenfant

\section{- To cite this version:}

F. Plard, J. M. Gaillard, T. Coulson, A. J. Hewison, M. Douhard, et al.. The influence of birth date via body mass on individual fitness in a long-lived mammal. Ecology, 2015, 96 (6), pp.1516-1528. 10.1890/14-0106.1 . hal-02018989

\section{HAL Id: hal-02018989 \\ https://univ-lyon1.hal.science/hal-02018989}

Submitted on 27 May 2020

HAL is a multi-disciplinary open access archive for the deposit and dissemination of scientific research documents, whether they are published or not. The documents may come from teaching and research institutions in France or abroad, or from public or private research centers.
L'archive ouverte pluridisciplinaire HAL, est destinée au dépôt et à la diffusion de documents scientifiques de niveau recherche, publiés ou non, émanant des établissements d'enseignement et de recherche français ou étrangers, des laboratoires publics ou privés. 


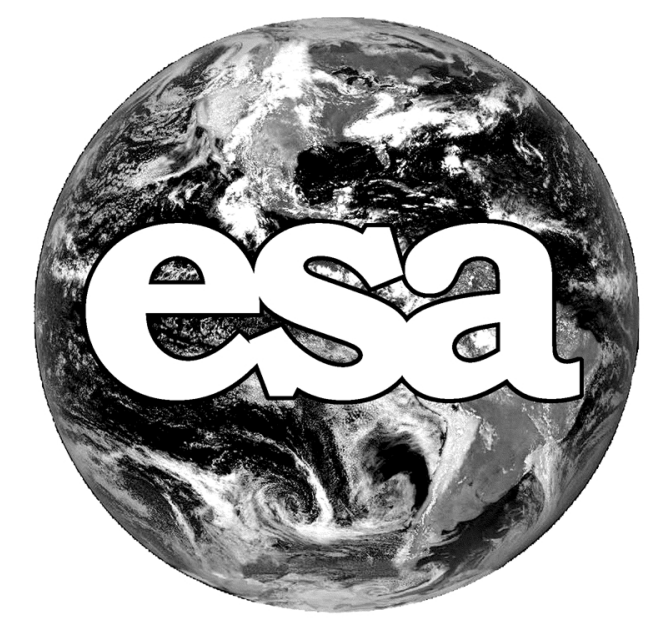

\section{ECOLOGICAL \\ SOCIETY \\ OF AMERICA}

Ecology/Ecological Monographs/Ecological Applications

\section{PREPRINT}

This preprint is a PDF of a manuscript that has been accepted for publication in an ESA journal. It is the final version that was uploaded and approved by the author(s). While the paper has been through the usual rigorous peer review process of ESA journals, it has not been copy-edited, nor have the graphics and tables been modified for final publication. Also note that the paper may refer to online Appendices and/or Supplements that are not yet available. We have posted this preliminary version of the manuscript online in the interest of making the scientific findings available for distribution and citation as quickly as possible following acceptance. However, readers should be aware that the final, published version will look different from this version and may also have some differences in content.

The doi for this manuscript and the correct format for citing the paper are given at the top of the online (html) abstract.

Once the final published version of this paper is posted online, it will replace the preliminary version at the specified doi. 


\title{
1. The influence of birth date via body mass on individual fitness in a long-lived mammal
}

\author{
Floriane Plard $^{1, *}$, JeAn-Michel Gaillard ${ }^{1}$, Tim Coulson $^{2}$, A. .
} J. Mark Hewison ${ }^{3}$, Mathieu Douhard ${ }^{1}$, François KLein ${ }^{4}$, Daniel DELORME $^{4}$, Claude WARNANT ${ }^{4}$, AND Christophe BONENFANT ${ }^{1}$

${ }^{1}$ Université de Lyon, F-69000, Lyon; Université Lyon 1; CNRS, UMR5558, Laboratoire de Biométrie et Biologie Évolutive, F-69622, Villeurbanne, France.

${ }^{2}$ Department of Zoology, University of Oxford, The Tinbergen Building, South Parks Road, Oxford, OX1 3PS, United Kingdom

${ }^{3}$ INRA, UR035 CEFS, B.P. 52627, 31326 Castanet-Tolosan cedex, France

${ }^{4}$ Centre National d'Études et de Recherches Appliquées sur les Cervidés et Sanglier, Office National de la Chasse et de la Faune Sauvage, 85bis avenue de Wagram, 75017 Paris, France

\footnotetext{
*Email: floriane.plard@ens-lyon.fr
} 
Abstract. The timing of birth has marked impacts on early life and early development of newborns in many species. Early-born offspring often survive and grow better than late-born offspring, but despite the long-lasting effects of early conditions on life history traits, the influence of birth date on fitness has rarely been investigated for long-lived species. In this study, we analyzed both the short- and long-term effects of birth date on individual life history traits and explored its subsequent impact on individual fitness in a population of roe deer. We considered both the direct effects, as well as the indirect effects of birth date mediated through the effects of body mass, on demographic parameters. We found that in addition to short-term effects on early body growth and survival, birth date generates "silver spoon" effects on adult life history traits of female roe deer. Birth date had long-lasting effects on female adult body mass such that early-born females were, on average, $3 \mathrm{~kg}$ heavier as adults than late-born females, although female adult survival was similar between these categories. Based on the observed relationships between birth date, body mass and demographic parameters, we built an integral projection model describing the simultaneous distributions of birth date and body mass to quantify the fitness consequences of birth date. We found that the fitness of early-born females was higher than that of late-born females. These long-lasting effects of birth date on fitness were mostly mediated through the influence of birth date on recruitment and adult body mass. By determining development of newborns during the early stages of life, birth date has a critical influence on each step of an individual's subsequent life history trajectory.

Key words: silver spoon effect, life history traits, IPM, roe deer, body mass 


\section{INTRODUCTION}

The suc tim

(Di resource availability decreases annual recruitment (Post and Forchhammer 2008). At the population level, a high degree of birth synchrony may be the result of selection pressure on individuals to minimize this mismatch (Rutberg 1987) or, alternatively, be linked to a predator-swamping tactic (Estes 1976, Ims 1990). Indeed, in temperate areas, births are generally characterized by a high degree of seasonality and synchrony each year (Bronson 1989). However, within population variation in individual birth date has the potential to influence greatly early survival and body growth. Because body growth affects adult life history traits, birth date is expected to generate long-term effects on fitness (Lindström 1999, Cam and Aubry 2011). To date, most studies have focused on the short-term consequences of variation in individual birth date on the early stages of life, while evidence for long-term effects of birth date on adult life history stages and on fitness are lacking for long-lived species (Green and Rothstein 1993, Lindström 1999, Cam and Aubry 2011). In this paper, we thus investigated the long-term effects of individual birth date on adult life history traits and individual fitness.

Yearly variation in weather conditions influences both the quality and the quantity of available resources during the period around birth. In temperate and northern areas, early-born young benefit from a longer growth period and attain a higher body mass before the onset of the harsh season than neonates born after the peak of vegetation production (moose Alces alces, Solberg et al. 2007, bighorn sheep, Ovis canadensis Feder et al. 2008). For example, in bighorn sheep, late-born lambs were $20 \%$ lighter in mid-September, at 3 months of age than lambs born one month earlier (Feder et al. 2008). For a given individual, being born early in the season also has 
positive effects on early survival in many species (red deer, Cervus elaphus, Guinness et al. 1978, western gulls, Larus occidentalis, Spear and Nur 1994, mosquitofish, Gambusia affinis, Reznick et al. 2006). For instance, the probability of surviving until the end of the first winter for red deer calves born very early was more than double that of calves born very late in the season (Guinness et al. 1978). In some cases, young born very early in the season may encounter harsh environmental conditions (Wilson et al. 2005) or suffer from higher predation (Estes 1976) than young born during the peak of births. However, as a general rule, late-born young have a lower early survival than individuals born early or during the birth peak in most large herbivores and passerine birds.

Because it affects the early body development of young which, in turn, often determines performance during adulthood (Douhard et al. 2013), date of birth has the potential to generate long-term effects on adult phenotypic traits, but this question has seldom been investigated in long-lived species. Indeed, a link between reproductive timing and fitness components has been demonstrated for short-lived species (hatching date in lizard (Sinervo and Doughty 1996), birth date in fish (Schultz 1993, Reznick et al. 2006) hatching date and fledging date in birds (Visser and Verboven 1999, Sheldon et al. 2003, Saino et al. 2012) and birth date in small mammals (Réale et al. 2003, Rödel et al. 2009)). However, the long-term effects of environmental conditions in early life on adult life history traits are not universal (e.g., Wauters and Dhondt 1995 on European squirrels, Dobson et al. 1999 on Columbian ground squirrels) because some individuals born in poor conditions can compensate for a bad start (Auer 2010 on guppies). Nevertheless, poor early conditions may also permanently constrain body growth and generate positive covariation among adult life history traits (the "silver spoon effect", Grafen 1988) in long-lived species. For instance, environmental conditions at birth influence both early survival and growth (Gaillard et al. 2003, Landete-Castillejos et al. 2001, Beauplet et al. 2005), but also adult life history traits such as body mass (roe deer, Capreolus capreolus, Pettorelli et al. 2002), and lifetime reproductive success (red deer, Kruuk et al. 1999, oystercatchers, Haematopus 
ostralegus, Van de Pol et al. 2006).

As a consequence of the long-term effects of early life conditions on life histories, females born early should have high early survival and, when adult, could themselves give birth early in the season. Because birth date and laying date have been found to be heritable (Réale et al. 2003, Sheldon et al. 2003), the young of these early-born females should therefore also have high early survival, so that early-born females should achieve higher fitness than late-born females. Moreover, in species for which adult body mass is positively correlated with juvenile body mass, females born early in the season should also be heavier, and so produce larger average litter sizes, than late-born females. While such relationships are often assumed in studies using laying (or birth) date as a proxy of female quality (Sydeman and Eddy 1995, Catry et al. 1999, Blums et al. 2005), very few studies have explicitly investigated the relationship between reproductive timing and individual fitness. In the present study, we defined individual fitness as the individual reproductive value early in life (Moorad 2014, see also Methods for a justification of this measure).

In this study, we investigated both the short-term and long-term effects of birth date on individual life history traits and on fitness in an intensively monitored population of long-lived mammals, roe deer. We tested the following hypotheses: (i) as predicted from the match between early growth and resource availability (Rutberg 1987), early-born fawns should survive better and have higher early body growth than late-born fawns because the former benefit from high quality resources (Plard et al. 2014a), (ii) early-born individuals should be heavier when adults, gain higher annual reproductive success, and live longer than late-born individuals because early conditions have the potential to generate "silver spoon" effects (Grafen 1988). Finally, using the observed relationships between birth date, body mass and demographic parameters, we built an integral projection model (Easterling et al. 2000) to analyse the link between birth date and fitness. We used an IPM (instead of a classical analysis of lifetime reproductive success) for the following reasons: the IPM allowed us to estimate reproductive 
value early in life for each birth date and to identify the exact pathways (i.e. survival, reproduction, growth, or inheritance) by which birth date influences fitness. Moreover, by building an IPM based on the distribution of two continuous traits, we could investigate both the direct influence of birth date on fitness through its effect on annual reproductive success and survival, as well as the indirect influence of birth date on fitness through its effect on body mass. (iii) As long-lasting effects of early life often occur through permanent developmental constraints (Lummaa and Clutton-Brock 2002), early-born individuals should achieve higher fitness than late-born individuals, mainly because of the positive association between early birth and fast body growth (e.g., Feder et al. 2008).

\section{MATERIALS AND METHODS \\ Study population}

The roe deer population at Trois Fontaines inhabits an enclosed 1,360ha forest in north-eastern France $\left(48^{\circ} 43^{\prime} \mathrm{N}, 2^{\circ} 61^{\prime} \mathrm{W}\right)$. The climate is continental, with relatively cold winters and warm summers. This roe deer population has been intensively monitored since 1976 using a Capture-Mark-Recapture (CMR) sampling design. Captured animals are individually marked using collars (numbered or with VHF or GPS devices) and ear tags. The roe deer population at Trois Fontaines is highly productive, mostly because of the rich habitats and soils which promote high forest productivity (Pettorelli et al. 2006). Roe deer mate between mid-July and mid-August. After copulation, embryos cease their development so that their implantation is delayed by a five month diapause. Embryo development starts again in late December-early January (Aitken 1974). Births in roe deer are highly seasonal, synchronous and occur from mid-April to mid-June, with $80 \%$ of births taking place between the $5^{\text {th }}$ and $27^{\text {th }}$ of May at Trois Fontaines (Gaillard et al. 1993). Birth dates are normally distributed, with a median birth date of May $16^{\text {th }}$. Females are monoestrous and give birth to one, two, or occasionally three fawns 
(triplets accounted for only about $2 \%$ of the litters), once per year, from 2 years of age onwards.

\section{Date of birth}

From the beginning of the birthing season (mid-April), a systematic search for fawns was conducted every year from 1985 to 2012 by the Office National de la Chasse et de la Faune Sauvage (Delorme et al. 1988). Between 21 and 63 newborn fawns were found each year through either intensive searches performed by a line of people, or by directed searches targeted towards the fawns of radio-collared females. Fawns were ear-tagged, weighed, sexed and aged using umbilicus characteristics and behavior at marking (Jullien et al. 1992). Error when estimating capture age is less than 2 days (Gaillard et al. 1993). Birth date was therefore back-calculated based on the fawn's estimated age at the date it was found. Body mass at capture did not allow us to estimate body mass at birth because early growth rates vary among fawns. Roe deer fawns display a "hider" tactic (Lent 1974), only coming into close contact with the mother for suckling. However, the mother stays in close proximity to its fawns, remaining spatially isolated from other females. We relied on this behaviour to identify the fawn's mother through direct observation of lactation behavior or by identification of an escaping female in the vicinity of the fawn. We assumed that the body mass of a given fawn at first capture measured between early January

\section{Life history traits}

Winter captures of roe deer took place each year between January and mid-March. At each capture, animals were weighed to the nearest $100 \mathrm{~g}$. Yearling and adult body masses corresponded respectively to the body mass of a given female at 8 months old (i.e. at first winter capture) and to its median mass as an adult between 4 and 10 years old (Pettorelli et al. 2002). and early March provides a reliable estimate of its body mass at 8 months of age because body mass remains almost constant over the winter in roe deer (Hewison et al. 2002). The annual 
1 reproductive success of each female was assessed by the capture of its marked fawns at 8

months old. As we did not have access to father-fawn filiations, and thus to male reproductive success, we only included females for the analysis of the effect of birth date on adult stage traits. The age of all reproducing females analyzed here was known exactly because they were first captured either as newborns or at 8 months of age during their first winter (identified using tooth eruption sequence, Flerov (1952)).

\section{Statistical analysis}

To investigate short- and long-term influences of birth date on female life history traits and fitness, we considered both the direct effect of birth date on demographic parameters (survival, reproduction) and the indirect effect of birth date on demographic parameters mediated through its effect on body mass (see Fig. 1). Thus, we tested for both an effect of individual birth date and of body mass (as a yearling or as an adult) on female adult body mass and annual survival. For early life stage traits, we investigated the short-term influence of individual birth date on early survival (survival from birth to 8 months old) and yearling survival, and yearling body mass. In addition, as heavy mothers give birth earlier than light mothers in roe deer (Plard et al. 2014b), we considered the relationship between maternal body mass and early life history traits of her offspring to control for possible maternal effects. Because these relationships included information on both mother and newborn fawns, we included both male and female newborns and corrected for sex when necessary to increase our sample size. There is no cost of being born very early in the season in roe deer because the earliest born fawns have the highest early survival (Plard et al. 2014a) and the highest yearling body mass, which is highly positively correlated to yearling survival in ungulates (Gaillard et al. 2000b). We thus tested for the linear effect of birth date on yearling and adult body masses, and on adult survival. Moreover, we have previously shown that early survival is linked to birth date through a threshold relationship (Plard et al. 2014a). As we expected a directional effect of body mass on life history traits, we 
only tested for linear effects of body mass.

Birth date and early life stage traits: The influence of birth date and maternal body mass on individual early survival (proportion of fawns of each litter that survived up to 8 months of age) was investigated using a generalized linear mixed model with a logit link and a binomial distribution. Because there is no difference between the sexes in individual early survival in roe deer (mean survival difference: 0.13, SE: 0.25, p-value: 0.61, see also Gaillard et al. (1997)), we pooled fawns of both sexes in this analysis. We modeled a threshold regression for birth date (with constant survival until the $12^{\text {th }}$ of May, then decreasing from this birth date onwards, (Plard et al. 2014a)) and a linear regression for maternal body mass on individual early survival. The influence of birth date and maternal body mass on yearling body mass was modeled using linear mixed models. As males are heavier than females at 8 months of age in roe deer (Gaillard et al. 1996), we included an effect of sex. In models describing individual early survival and yearling body mass, we included cohort as a random effect on the intercept to control for among-year variation in environmental conditions and maternal identity as a random effect to control for the fact that among-female heterogeneity in reproductive performance is partly unrelated to body mass and birth date. The influence of a female's birth date and yearling body mass on its yearling survival (i.e. from 8 to 20 months old) was investigated using a generalized linear mixed model, including cohort as a random effect.

Birth date and adult stage traits: To investigate whether individual birth date has a direct effect on female adult body mass (over and above its indirect effect on adult body mass mediated through its effect on individual yearling body mass), we performed a path analysis (Shipley 2009). In all models, we included an influence of individual birth date on yearling body mass and tested for direct effects of both individual birth date and yearling body mass on individual adult body mass using a linear model, including only females. The influence of a female's birth date and adult body mass on its adult survival was tested using a capture-mark-recapture (CMR) framework. Models were fitted using capture histories of 110 
females in the software ESURGE (Choquet et al. 2009). Based on previous studies in this population (e.g., Choquet et al. 2011), recapture probability was modeled for 3 discrete time periods (1986-1999, 2000, 2001-2012).

For each life history trait except adult body mass, the best model was selected using the Akaike Information Criterion (AIC, Burnham and Anderson 2002). We selected the model with the lowest AIC and highest AIC weight $\left(w_{i}\right.$, calculated as a measure of the likelihood that a given candidate model is the best among the set of fitted models). For modeling adult body mass, we used a path analysis in a Bayesian framework (Gelman and Hill 2007) with OpenBUGS and tested for both the influence of yearling body mass and for the direct effect of individual birth date on adult body mass using the Deviance Information Criterion (DIC, following Gelman and Hill 2007, see also Spiegelhalter et al. 2002). We conducted 20000 simulations and used the first 5000 as burn-in. We checked that the parameters estimated from the models we fitted were not influenced by multi-colinearity problems (especially between birth date and body mass). We compared the values of body mass and birth date estimated from models with and without body mass and birth date included. Estimates were similar in all models. Diagnostic plots displaying the residuals of each selected model are presented in the supplementary material (Fig. A3 and A4).

Birth date and individual fitness. To investigate the influence of birth date on fitness (measured using reproductive value early in life), we used an integral projection model (IPM) to analyse the dynamics of the distributions of two continuous traits over time (Easterling et al. 2000, Ellner and Rees 2006, Coulson 2012): body mass ( $\mathrm{bm}$ ) and birth date (bd), for female roe deer in the population of Trois Fontaines. The contemporaneous distributions of body mass and birth date at year $t+1$ according to their age $a+1$ (the proportion of individuals of age $a+1$ and class $(b m, b d)$ at year $t+1$ in the population is defined by $\mathbf{n}(a+1, t+1, b m, b d))$ depend on their distributions at year $t$ and on five functions: (1) the inheritance function for birth date $\left(\mathbf{I}_{\mathbf{b d}}\left(a, t, b m, b d^{\prime} \mid b d\right)\right)$ links the offspring's birth date to the birth date and body mass of the 
mother. Following standard terminology in the IPM literature (Coulson et al. 2011, Coulson 2012), we defined inheritance as the part of the trait that is transmitted from mothers to offspring, irrespective of the mechanism of transmission. This measure includes all environmental sources of similarity (e.g., maternal effects, common habitat effects, permanent environment effects) and, is equivalent to "inclusive heritability" (sensu Danchin et al. 2011). (2) The recruitment function ( $\left.\mathbf{R}\left(a, t, b m, b d^{\prime}\right)\right)$ describes the number of offspring a mother successfully raised as a function of their birth date and the mother's body mass. (3) The inheritance function for body mass $\left(\mathbf{I}_{\mathbf{b m}}\left(a, t, b m^{\prime} \mid b m, b d^{\prime}\right)\right)$ links an offspring's body mass at 8 months of age (yearling body mass) to its birth date and maternal body mass. (4) The growth function $\left(\mathbf{G}\left(a, t, b m^{\prime} \mid b m, b d\right)\right)$ describes the individual-level relationship between body mass as a yearling and body mass as an adult, given that individual's birth date. As birth date is unique for a given individual, the growth function included also an implicit developmental function for birth date defined as an identity function. Finally, (5) the survival function $(\mathbf{S}(a, t, b m, b d))$ describes the probability that an individual survives in relation to its birth date and body mass. Then:

$\mathbf{n}\left(1, t+1, b m^{\prime}, b d^{\prime}\right)=\sum_{a} \iint \mathbf{I}_{\mathbf{b m}}\left(a, t, b m^{\prime} \mid b m, b d^{\prime}\right) \mathbf{R}\left(a, t, b m, b d^{\prime}\right) \mathbf{I}_{\mathbf{b d}}\left(a, t, b m, b d^{\prime} \mid b d\right) \mathbf{n}(a, t, b m, b d) d b m d b d$ $\mathbf{n}\left(a+1, t+1, b m^{\prime}, b d\right)=\iint \mathbf{G}\left(a, t, b m^{\prime} \mid b m, b d\right) \mathbf{S}(a, t, b m, b d) \mathbf{n}(a, t, b m, b d) d b m d b d, a \geq 1$

The continuous IPM can be approximated as a high dimensional discrete matrix (Easterling et al. 2000, see also supplementary material, Fig. B2). To minimize the size of the matrix, we used a two age-class structure: yearling (1 year old) and adult females (Nilsen et al. 2009), illustrated in the Fig. B1. As adult body mass of an individual female varies little among years in roe deer (e.g. Andersen et al. 2000, Plard et al. 2014b), we assumed that an individual's body mass was constant from 2 years old to death and equal to its median adult body mass (between 4 and 10 years old), so limiting the size of the matrix to two age classes. While this assumption may lead to a slight over-estimate of body mass for 2 and 3 year old individuals and for females older than 10 years old, this is unlikely to overly influence our analyses. Roe deer females 
indeed reach $93 \%$ of their adult body mass at 2 years of age and body mass of senescent females is $96 \%$ of their adult body mass (a decrease of $1 \mathrm{~kg}$ on average, Hewison et al. 2011). All functions required to build the IPM were investigated in the previous analyses (i.e. on birth date and early life stage traits and on birth date and adult stage traits) except the inheritance function for birth date. We thus used the parameters (intercepts and slopes) previously estimated from the selected models of early and adult life history traits (Table B1, Fig. 1) for the survival, growth, inheritance for body mass and recruitment functions and investigated the effects of maternal birth date and body mass on the inheritance function for birth date to build the IPM. For the inheritance function for birth date, we modeled the link between offspring birth date and maternal birth date and body mass using a linear mixed model, including year and maternal identity as random effects on the intercept. Sex was not included as there is no difference in average birth date between male and female roe deer (Gaillard et al. 1993). As almost all roe deer females give birth to two fawns in the studied population (Gaillard et al. 1998), we considered litter size at birth as a fixed parameter and modeled the recruitment function based solely on estimates of early survival from birth to the onset of winter (at 8 months of age). As the sex ratio at birth of roe deer is close to 0.5 (Hewison et al. 1999), litter size at birth was set to one as only females were considered in the IPM. We modeled both the inheritance and the growth functions using a normal probability density. The mean of each of these functions provides the link between the offspring trait and the maternal trait (including the effect of the individual's birth date for the inheritance function for body mass) for the inheritance functions and between an individual's adult body mass and its yearling body mass and its birth date for the growth function. The variances of these functions were estimated from the squared residuals of the mean relationships and were kept constant.

We quantified the influence of birth date on fitness by estimating the individual reproductive value of roe deer at 8 months of age in relation to their birth date. Reproductive value was first introduced by Fisher (1930) to measure the extent to which individuals of different ages 
contribute to future population growth. For a large population living in a constant environment, the sum of the reproductive values over all individuals is proportional to the exponential growth rate $r$ (i.e. Malthusian growth rate) of the population irrespective of its age distribution (Fisher 1930, Engen et al. 2009). For instance, reproductive values were recently used as a metric of fitness in different contexts (see e.g. Engen et al. 2009; 2012, Bouwhuis et al. 2012). Moreover, assuming that the population growth rate is constant, reproductive value at birth measures individual fitness (Moorad 2014). We therefore chose reproductive value in early life to measure fitness and not the more commonly used asymptotic population growth rate (r) (Caswell 2001). Indeed, the life cycle of roe deer used in our analysis (Fig B1) corresponds precisely to the model where maximizing reproductive value is equivalent to maximizing fitness (Caswell 2001). Moreover, using an integral projection model allowed us to generate a given reproductive value for each birth date class, whereas we had only one asymptotic population growth rate for the entire population. As noted by Fisher himself, $r$ is the average individual fitness and is therefore a property of the population. This measure can be biased when used at the individual level because the average of individual measures (individual $r$ ) is not equal to the asymptotic population growth rate. Moreover, in contrast to other commonly used measures of individual fitness like lifetime reproductive success (Clutton-Brock 1988, Newton 1989), reproductive values account for how much a given heritable genotype will contribute to future generations (Maciejewski 2014) and for the timing of reproduction. In long-lived species for instance, two individuals that successfully raised the same number of offspring during their lifetime, but at different ages, have the same lifetime reproductive success but different reproductive values when population growth differs from 0 .

Given the available data, we estimated reproductive values at 8 months of age rather than at birth as commonly done. Indeed, we did not have measures of body mass at birth for most individuals monitored, which were first weighed at 8 months of age and recruited then in our demographic model (see the definition of the recruitment function). We approximated reproductive values at 
birth as the reproductive values at 8 months, which means that we underestimated the influence of birth date on fitness by not accounting for the influence of birth date on early survival (Plard et al. 2014a). To estimate the confidence interval of the individual reproductive values, we performed a bootstrap analysis with 2000 simulations of the datasets used to estimate the different functions of the IPM (except for adult survival that remained constant with respect to body mass and birth date, see results). Second, to investigate the relative influence of each function on the difference in fitness between early- and late-born individuals, we performed a perturbation analysis. We estimated the percentage change in the difference in fitness between early- and late-born females after a $1 \%$ change of one of the slopes linking birth date and body mass to the vital rates. Finally, we simulated 60 groups of 1000 yearling females which differed in terms of their birth date and that were monitored until the death for all individuals in the group. For each group, we recorded mean adult body mass, annual reproductive success, and both mean female offspring body mass and life expectancy at 8 months of age as predicted by the IPM. All statistical analyses were performed with the R software from codes (available in the supplementaL material) that we wrote based on Easterling et al. (2000) and Coulson (2012).

\section{RESULTS}

\section{Birth date and early life stage traits}

Early survival of individual fawns was best described by a model that included additive effects of individual birth date and maternal body mass (Table $1 \mathrm{~A}, w_{i}=0.67, \mathrm{~N}=256$ including 120 different mothers with 2.1 repetitions per mother on average). Fawns born before $12^{\text {th }}$ May had a probability of 0.52 [0.42;0.61], on average, of surviving to 8 months old. Early survival probability decreased from this date onwards such that fawns born late in the season (May, $31^{\text {st }}$, Fig. 2A) had a probability of only 0.32 [0.20;0.48], on average, of surviving to the same age (Table A1A and Fig. 2A). Maternal body mass influenced early survival positively (Table A1A) 
such that fawns born to mothers weighing $20 \mathrm{~kg}$ had, on average a 0.25 [0.14;0.40] probability of surviving, while those born to mothers weighing $28 \mathrm{~kg}$ had, on average, a 0.71 [0.54;0.83] probability of surviving (for fawns born at the peak of the birth season). This model accounted for $6 \%$ (of which, $1 \%$ was due to the effect of birth date) of the observed variation in early survival (note that the proportion of variation explained for a binomial response variable is always much lower than that for a Gaussian variable).

Individual yearling body mass was best described by a model that included additive effects of maternal body mass and individual birth date (Table 1B, $w_{i}=0.98, \mathrm{~N}=111$ including 67 different mothers with 1.6 repetitions per mother on average) and which explained $26 \%$ (of which, $9 \%$ was due to the effect of birth date) of the observed variation in yearling body mass. Early-born fawns ( $\left(1^{\text {st }}\right.$ May) were $2.9 \mathrm{~kg}(20 \%)$ [1;4.9 kg] heavier, on average, at 8 months of age than late-born fawns ( $31^{\text {st }}$ May) (Table A1B and Fig. 2B). Moreover, for a given birth date, heavy mothers $(28 \mathrm{~kg}$ ) produced offspring that were, on average, $3.1 \mathrm{~kg}(21.5 \%)[0.6 ; 5.6 \mathrm{~kg}]$ heavier at 8 months of age than light $(20 \mathrm{~kg})$ mothers. Nevertheless, our diagnostic plot (Fig. A3) showed that the residuals of the regression tended to increase with the fitted values. This trend was directly linked to the random individual (maternal) effect, suggesting that an unidentified variable related to a maternal effect could influence the inheritance of body mass. The best model describing individual yearling survival from 1 to 2 years of age included an effect of individual yearling body mass (Table $1 \mathrm{C}, w_{i}=0.44, \mathrm{~N}=113$ ). Heavier yearlings had a higher probability of surviving to 2 years of age than lighter yearlings ( 0.89 vs. 0.99 for yearlings of $12 \mathrm{~kg}$ and $20 \mathrm{~kg}$, respectively, Fig. A4). Adding birth date did not improve the model fit, which indicates that birth date has no detectable effect on yearling survival.

\section{Birth date and adult stage traits}

The best model describing individual adult body mass included additive effects of birth date together with the indirect effect of birth date on adult body mass mediated through yearling 
body mass (Table 1D, N=67). The retained model accounted for $50 \%$ of the observed variation in adult body mass, of which $6 \%$ was explained by the direct effect of individual birth date (Table A1D). Whether or not we included the two individuals with an adult body mass of $18 \mathrm{~kg}$ that appear as outliers in Fig. 3 had no influence on model selection or parameter estimates. When considering only the direct effect of birth date on adult body mass, early-born individuals $\left(1^{\text {st }}\right.$ May) reached a body mass that was $6.5 \%$ higher than late-born individuals ( $31^{\text {st }}$ May) (24.0 kg vs. 22.5 kg, Fig. 3). However, individual birth date influenced adult body mass mainly through its effect on yearling body mass which was a better predictor of adult body mass than birth date $(\triangle D I C=40.6$ if we removed the effect of yearling body mass from the best model vs. $\triangle D I C=1.4$ if we removed the effect of birth date from the best model, Table 1D). A yearling weighing $12 \mathrm{~kg}$ reached an adult body mass of, on average, $20.8 \mathrm{~kg}$, whereas a yearling weighing $20 \mathrm{~kg}$ weighed, on average, $25.8 \mathrm{~kg}$ as an adult. As effects of female birth date or body mass on individual adult survival were non-significant (Table 1E, Table A1E, N=110), we used all monitored females to estimate an overall adult survival probability $(\mathrm{N}=418)$. The annual survival rate of adult females was $0.824[0.796 ; 0.850]$ (Fig. A1).

\section{Birth date and fitness}

We built an IPM from the parameter estimates that we generated above for each function (Table B1). For the inheritance function for birth date, offspring birth date was positively related to maternal birth date (Table A2, $w_{i}=0.35, \mathrm{~N}=89$ including 33 different mothers with 2.7 repetitions per mother on average) such that females born early in the season ( $1^{\text {st }}$ May) gave birth, on average, $5[-2 ; 13]$ days earlier than females born late ( $31^{\text {st }}$ May) in the season (Fig. A2). Five per cent of the observed variation in offspring birth date was explained by this model. The diagnostic plot of this model showed a trend between the residuals and the fitted values (Fig. A3), probably for the same reason as the trend observed in the diagnostic plot of the 
model for the inheritance function for body mass.

We evaluated the stable distribution of body mass and birth date from the right eigenvector of the projection matrix. The stable distribution of body mass revealed two peaks corresponding to a mean body mass of $16 \mathrm{~kg}$ and $23 \mathrm{~kg}$ for yearling and adult female roe deer, respectively (Fig. C1A). The stable distribution of yearling birth dates was also in agreement with field observations, with a mean birth date of $135.5\left(15-16^{\text {th }}\right.$ May vs. $16^{\text {th }}$ May for the observed mean birth date of newborns in this population) and a normal distribution of birth dates (Fig. C1B). Using this IPM allowed us to estimate reproductive value at 8 months of age, and thereby fitness, of females in relation to their birth date (Fig. C2). We report here the relative change in reproductive value (and not absolute estimations of reproductive value) between early- and late-born individuals because reproductive values should be interpreted as relative values. We estimated that the fitness of early-born females ( $1^{\text {st }}$ May) was 1.29 (95\% confidence interval: [1.01 3.47]) higher than that of late-born females ( $31^{\text {st }}$ May). The perturbation analysis showed that birth date had both a direct effect (on early survival and inheritance) and an indirect effect (through body mass) on fitness (Fig. 4). Indeed, the difference in fitness between early- and late-born individuals was closely related to the slopes linking birth date to early survival (when we decreased the slope of the recruitment function for birth date by $1 \%$, the difference in fitness between early- and late born females increased by $0.61 \%$ ) and linking maternal birth date to offspring birth date (a 1\% change in the slope of the inheritance function for birth date led to a $0.40 \%$ change in the difference in fitness). This difference was also closely related to the indirect effect of birth date on fitness mediated through body mass. Indeed, a 1\% change in the slope of the growth function for birth date and in the inheritance function for body mass led to a $0.35 \%$ and to a $0.21 \%$ change in the difference in fitness between early- and late-born females, respectively. Simulating 60 groups of yearlings born on different days indicated that early-born females ( $\left(1^{\text {st }}\right.$ May) weighed $3.3 \mathrm{~kg}(13 \%)$ more as adults than late-born females ( $31^{\text {st }}$ May). Moreover a $1 \%$ change in the slopes linking body mass and the vital rates led to a change in the 
difference in fitness between early- and late-born females of $0.50 \%$ for recruitment, $0.38 \%$ for growth and $0.07 \%$ for the inheritance function for body mass. Only the survival function contributed relatively little to the difference in fitness between early- and late-born females (Fig. 4). Because birth date had no statistically significant direct effects on survival but was weakly related to yearling survival through its effect on yearling body mass, life expectancy at 8 months of age was slightly higher for early-born individuals than for late-born individuals $(6.57+/-4.91$ vs. $6.41+/-4.93)$.

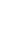

Usi b

$$
\text { f }
$$
of birth date in mammals are recent and confined to short-lived species (e.g. European rabbit Oryctolagus cuniculus, Rödel et al. 2009). Indeed, Wilson et al. (2005) found no evidence for direct effects of birth timing on fitness in the Soay sheep (Ovis aries), the only moderately long-lived mammal studied so far. Our results in a wild population of roe deer suggest that the timing of birth can have a strong long-term influence on life histories, even in long-lived species. Building an IPM based on the distribution of two contemporaneous traits allowed us to identify the relative contribution of each function (i.e. survival, recruitment, growth, and inheritance) to the difference in fitness observed between early- and late-born individuals. We found that the silver spoon effect of birth date in roe deer is generated by both the direct effect of birth date on recruitment and by the indirect effect of birth date on the different vital rates through body mass. The indirect effect of birth date on fitness through body mass is a crucial pathway, because the higher body mass that early-born fawns attained when adult mostly accounts for 
their higher fitness. Body mass has a strong influence on reproduction in large herbivores and is often directly linked to individual quality (Gaillard et al. 2000a, Hamel et al. 2009). As a consequence, compared to body mass, birth date per se only has a minor impact on the demography of the studied roe deer population. An IPM based on body mass only (i.e. without including birth date) would provide a reliable picture of the dynamics of this population but would not provide a mechanistic understanding of the influence of birth date on fitness. The IPM including both birth date and mass highlighted two key findings: (1) birth date plays a determinant role in shaping individual fitness, with early-born females enjoying higher fitness than late-born ones, and (2) the influence of birth date is mostly indirect, with the main pathway involving changes in body mass.

Birth date commonly affects early life history traits in many species (Guinness et al. 1978, Reznick et al. 2006, Feder et al. 2008, Solberg et al. 2007), including roe deer. Indeed, we found that birth date had a marked influence on early survival, with early-born fawns surviving much better than late-born individuals. Early-born fawns also reach a higher body mass as yearlings than late-born individuals. These short-term effects of birth date probably result from the high food quality available in early spring. The nutritional value of plants is high at the beginning of the growing season and decreases as they mature (Klein 1965, Albon and Langvatn 1992). Thus, early-born fawns have access to high quality milk, and in large quantities, from their mothers who have access to plentiful, highly digestible food resources. As a consequence, they reach a higher body mass as yearlings than late-born individuals. Long-lasting impacts of environmental conditions at birth have often been supposed to be mediated through early development (Lindström 1999, Kruuk et al. 1999). For instance, environmental conditions at birth affect both early and late body growth in male and female roe deer in two populations (Douhard et al. 2013). Similarly, birth date influences fitness of female roe deer through long-lasting effects on both juvenile and adult body masses in one of these populations. The indirect effect of birth date on adult body mass through yearling body mass is 
clearly related to the match between birth timing and food resource availability. Fawns of temperate areas that are born early grow for a longer time during the plant growing season and so survive better. The biological interpretation of the direct influence of birth date on adult body mass is more challenging, but the establishment of permanent physiological and metabolic functions during gestation and very early life could explain the direct effect of early conditions on adult life history traits (Lummaa and Clutton-Brock 2002). In particular, the development of muscle tissue up until the adult stage is linked to fetal and very early life conditions, because the number of muscle fibers is fixed at birth and strongly influenced by maternal nutrition (Du et al. 2010). Moreover, although natal dispersal is quite frequent in roe deer of both sexes (Gaillard et al. 2008, Debeffe et al. 2012), many fawns remain philopatric and settle on a home range that is contiguous or overlapping with their maternal home range (Strandgaard 1972). An alternative explanation for the direct effect involves the correlation between individual quality and habitat quality, which could thus at least partly explain the direct influence of early life on adult body mass. Our results contrast with those on Soay sheep where no direct influence of birth date on fitness was detected and the long-lasting effect of birth date was simply linked to birth mass (Wilson et al. 2005). The markedly fluctuating environmental conditions faced by the Soay sheep population (Coulson 2001) have a strong influence on annual body mass and could mask any direct long-term effect of birth date on fitness.

The influence of birth timing on adult life history traits has been intensively studied in birds. In the intensively studied barn swallow, a short-lived species ( $<6$ years in this study), hatching date was negatively associated with lifetime reproductive success (Saino et al. 2012). However, the biological link between reproductive timing and fitness differs between barn swallows and roe deer. In barn swallows, early hatched individuals are longer-lived than late hatched birds and thereby obtain higher lifetime reproductive success through a greater number of reproductive attempts. In contrast, in roe deer, we have shown that birth date has no effect on adult survival which, as a general rule, varies little among years in large mammals (Gaillard 
et al. 2000b, Gaillard and Yoccoz 2003). In roe deer, birth timing-related fitness differences among individuals arise because of variation in annual reproductive success rather than in reproductive lifespan. This difference in reproductive performance is likely linked to the $3 \mathrm{~kg}$ higher adult body mass of early-born females compared to late-born females. Thus, early-born females are more successful in raising their offspring (Andersen et al. 2000).

Females which are born the earliest, which are also the heaviest and attain the highest fitness, can be considered as the highest quality individuals (Hamel et al. 2009). Indeed, while a variety of mechanisms may link birth or hatching date to fitness, birth date can be considered as an important component of the multi-dimensional complex that describes individual quality (sensu Wilson and Nussey 2010). In roe deer, we have shown that birth date influences the whole life history trajectory of an individual. Nonetheless, one cannot predict an individual's trajectory from its birth date alone. Individual life history trajectories are shaped by both early environmental conditions (including birth date) and current environmental conditions (Tuljapurkar et al. 2009). The relative role of traits that are fixed at birth, such as maternal home range or environmental conditions at birth, versus traits that vary across an individual's lifetime in response to dynamic environmental variations remains to be quantified (Tuljapurkar et al. 2009, but see Helle et al. 2012 on the bank vole). In our models including both early and late life history traits, birth date explained a maximum of $9 \%$ of the observed variation in the life history traits that we studied. The large amount of unexplained variation in these life history traits can be assumed to be linked to either annual environmental conditions or stochastic variation. Yearly variation in environmental conditions affects annual body condition (McNamara and Houston 1996) and the environmental cues used by different species to time their reproduction (Reed et al. 2010). In a species like roe deer that displays little among-year variation in body mass, body condition (Andersen et al. 2000) or timing of birth (Plard et al. 2013), we expect that birth date and early life conditions would markedly influence individual life history trajectories. On the contrary, in a species that shows large among-year variation in annual body 
condition (bighorn sheep, Festa-Bianchet 1998) or in species with marked phenotypic plasticity (such as the great tit, Parus major, Nussey et al. 2005), the relative influence of current annual environmental conditions on life history trajectories should be higher than in roe deer.

4 Consequently, the magnitude of the long-lasting effects of early conditions for shaping

5 individual life history trajectories and population dynamics is likely to vary as a function of the 6 life history strategy of the species.

8 We are grateful to the Office National de la Chasse et de la Faune Sauvage and to the many volunteers 9 and colleagues who participated in the roe deer captures in winter and who gave their time to catching and monitoring fawns on the study site of Trois Fontaines. Tim Coulson was funded by an ERC advanced grant. We warmly thank Bernt Erik Saether and the Centre for Biodiversity Dynamics for financial support of the roe deer project. We thank Steve Dobson and two anonymous reviewers for constructive comments on a previous version of the manuscript. 


\section{LiterATURE CITED}

Aitken, R. J., 1974. Delayed implantation in roe deer (Capreolus capreolus). Journal of Reproduction and Fertility 39:225-233.

4 Albon, S. D. and R. Langvatn, 1992. Plant phenology and the benefits of migration in a temperate ungulate. Oikos 65:502-513.

Andersen, R., J.-M. Gaillard, J. D. C. Linnell, and P. Duncan, 2000. Factors affecting maternal care in an income breeder, the European roe deer. Journal of Animal Ecology 69:672-682.

Auer, S. K., 2010. Phenotypic plasticity in adult life-history strategies compensates for a poor start in life in trinidadian guppies (Poecilia reticulata). The American Naturalist 176:818-829.

Beauplet, G., C. Barbraud, M. Chambellant, and C. Guinet, 2005. Interannual variation in the post-weaning and juvenile survival of subantarctic fur seals: influence of pup sex, growth rate and oceanographic conditions. Journal of Animal Ecology 74:1160-1172.

Blums, P., J. D. Nichols, J. E. Hines, M. S. Lindberg, and A. Mednis, 2005. Individual quality, survival variation and patterns of phenotypic selection on body condition and timing of nesting in birds. Oecologia 143:365-376.

Bouwhuis, S., R. Choquet, B. C. Sheldon, and S. Verhulst, 2012. The forms and fitness cost of senescence: age-specific recapture, survival, reproduction, and reproductive value in a wild bird population. The American Naturalist 179:E15-27.

Bronson, F. H., 1989. Mammalian reproductive biology. University of Chicago Press, Chicago.

Burnham, K. P. and D. R. Anderson, 2002. Model selection and multimodel inference - A practical information-theoretic approach. 2nd, Springer-Verlag, New York, USA. 
Cam, E. and L. Aubry, 2011. Early development, recruitment and life history trajectory in long-lived birds. Journal of Ornithology 152:S187-S201.

Caswell, H., 2001. Matrix population models : construction, analysis, and interpretation. Sinauer Associates, Sunderland, Mass., second edition.

Catry, P., G. D. Ruxton, N. Ratcliffe, K. C. Hamer, and R. W. Furness, 1999. Short-lived repeatabilities in long-lived great skuas: implications for the study of individual quality. Oikos 84:473-479.

Choquet, R., L. Rouan, and R. Pradel, 2009. Modeling Demographic Processes in Marked Populations, Volume 3 of Springer Series: Environmental and Ecological Statistics, chapter Program E-SURGE: a software application for fitting Multievent models, pages 845-865. Thomson, David L. and Cooch, Evan G.and Conroy, Michael J., springer, dunedin edition.

Choquet, R., A. Viallefont, L. Rouan, K. Gaanoun, and J.-M. Gaillard, 2011. A semi-Markov model to assess reliably survival patterns from birth to death in free-ranging populations. Methods in Ecology and Evolution 2:383-389.

Clutton-Brock, T. H., 1988. Reproductive success : studies of individual variation in contrasting breeding systems. University of Chicago Press, Chicago.

Coulson, T., 2001. Age, sex, density, winter weather, and population crashes in Soay sheep. Science 292:1528-1531.

Coulson, T., 2012. Integral projections models, their construction and use in posing hypotheses in ecology. Oikos 121:1337-1350.

Coulson, T., D. R. MacNulty, D. R. Stahler, B. vonHoldt, R. K. Wayne, and D. W. Smith, 2011. Modeling effects of environmental change on wolf population dynamics, trait evolution, and life history. Science 334:1275-1278. 
Danchin, E., A. Charmantier, F. A. Champagne, A. Mesoudi, B. Pujol, and S. Blanchet, 2011. Beyond DNA: integrating inclusive inheritance into an extended theory of evolution. Nature Reviews. Genetics 12:475-486.

Debeffe, L., N. Morellet, B. Cargnelutti, B. Lourtet, R. Bon, J.-M. Gaillard, and A. J. M. Hewison, 2012. Condition-dependent natal dispersal in a large herbivore: heavier animals show a greater propensity to disperse and travel further. Journal of Animal Ecology 81:1327-1337.

Delorme, D., J.-M. Gaillard, and J.-M. Jullien, 1988. Intérêt de l'étude de la période juvénile pour le suivi de l'évolution d'une population de chevreuils (Capreolus capreolus). Gibier Faune Sauvage 5:15-26.

Dickey, M.-H., G. Gauthier, and M.-C. Cadieux, 2008. Climatic effects on the breeding phenology and reproductive success of an arctic-nesting goose species. Global Change Biology 14:1973-1985.

Dobson, F. S., T. S. Risch, and J. O. Murie, 1999. Increasing returns in the life history of Columbian ground squirrels. Journal of Animal Ecology 68:73-86.

Douhard, M., J.-M. Gaillard, D. Delorme, G. Capron, P. Duncan, F. Klein, and C. Bonenfant, 2013. Variation in adult body mass of roe deer: early environmental conditions influence early and late body growth of females. Ecology 94:1805-1814.

Du, M., J. Tong, J. Zhao, K. R. Underwood, M. Zhu, S. P. Ford, and P. W. Nathanielsz, 2010. Fetal programming of skeletal muscle development in ruminant animals. Journal of Aanimal Science 88:E51-E60.

Easterling, M. R., S. P. Ellner, and P. M. Dixon, 2000. Size-specific sensitivity: applying a new structured population model. Ecology 81:694-708. 
Ellner, S. P. and M. Rees, 2006. Integral projection models for species with complex demography. The American Naturalist 167:410-428.

Engen, S., R. Lande, B.-E. Saether, and F. S. Dobson, 2009. Reproductive value and the stochastic demography of age-structured populations. The American Naturalist 174:795-804.

Engen, S., B.-E. Saether, T. Kvalnes, and H. Jensen, 2012. Estimating fluctuating selection in age-structured populations. Journal of Evolutionary Biology 25:1487-1499.

Estes, R. D., 1976. The significance of breeding synchrony in the wildebeest. African Journal of Ecology 14:135-152.

Feder, C., J. G. A. Martin, M. Festa-Bianchet, C. Bérubé, and J. Jorgenson, 2008. Never too late? Consequences of late birthdate for mass and survival of bighorn lambs. Oecologia 156:773-781.

Festa-Bianchet, M., 1998. Condition-dependent reproductive success in bighorn ewes. Ecology Letters 1:91-94.

Fisher, R. A., 1930. The genetical theory of natural selection. The Clarendon Press, Oxford, England.

Flerov, K., 1952. Fauna of USSR: Mammals. vol. 1 no. 2. Musk deer and deer. Academy of sciences of the USSR, Leningrad .

Gaillard, J.-M., R. Andersen, D. Delorme, and J. D. C. Linnell, 1998. Family effects on growth and survival of juvenile roe deer. Ecology 79:2878-2889.

Gaillard, J.-M., J.-M. Boutin, D. Delorme, G. Van Laere, P. Duncan, and J.-D. Lebreton, 1997. Early survival in roe deer: causes and consequences of cohort variation in two contrasted populations. Oecologia 112:502-513. 
Gaillard, J.-M., D. Delorme, J.-M. Boutin, G. van Laere, and B. Boisaubert, 1996. Body mass of roe deer fawns during winter in 2 contrasting populations. the Journal of Wildlife Management 60:29-39.

Gaillard, J.-M., D. Delorme, J.-M. Jullien, and D. Tatin, 1993. Timing and synchrony of births in roe deer. Journal of Mammalogy 74:738-744.

Gaillard, J.-M., M. Festa-Bianchet, D. Delorme, and J. Jorgenson, 2000a. Body mass and individual fitness in female ungulates: bigger is not always better. Proceedings of the Royal Society B: Biological Sciences 267:471-477.

Gaillard, J.-M., M. Festa-Bianchet, N. G. Yoccoz, A. Loison, and C. Toïgo, 2000b. Temporal variation in fitness components and population dynamics of large herbivores. Annual Review of Ecology and Systematics 31:367-393.

Gaillard, J.-M., A. J. M. Hewison, P. Kjellander, N. Pettorelli, C. Bonenfant, B. V. Moorter, O. Liberg, H. Andren, G. V. Laere, F. Klein, et al., 2008. Population density and sex do not influence fine-scale natal dispersal in roe deer. Proceedings of the Royal Society B: Biological Sciences 275:2025.

Gaillard, J. M., A. Loison, C. Toïgo, D. Delorme, and G. Van Laere, 2003. Cohort effects and deer population dynamics. Écoscience 10:312-320.

Gaillard, J.-M. and N. G. Yoccoz, 2003. Temporal variation in survival of mammals: a case of environmental canalization? Ecology 84:3294-3306.

Gelman, A. and J. Hill, 2007. Data analysis using regression and multilevel/hierarchical models. Cambridge University Press, New York.

Grafen, A., 1988. On the uses of data on lifetime reproductive success. In T. H. Clutton-Brock, 
editor, Reproductive success : studies of individual variation in contrasting breeding systems, pages 454-471. University of Chicago Press, Chicago.

Green, W. C. H. and A. Rothstein, 1993. Persistent influences of birth date on dominance, growth and reproductive success in bison. Journal of Zoology 230:177-186.

Guinness, F. E., T. H. Clutton-Brock, and S. D. Albon, 1978. Factors affecting calf mortality in red deer (Cervus elaphus). Journal of Animal Ecology 47:817-832.

Hamel, S., J.-M. Gaillard, M. Festa-Bianchet, and S. D. Côté, 2009. Individual quality, early-life conditions, and reproductive success in contrasted populations of large herbivores. Ecology 90:1981-1995.

Helle, H., E. Koskela, and T. Mappes, 2012. Life in varying environments: experimental evidence for delayed effects of juvenile environment on adult life history. The Journal of animal ecology 81:573-582.

Hewison, A. J. M., R. Andersen, J.-M. Gaillard, J. D. C. Linnell, and D. Delorme, 1999. Contradictory findings in studies of sex ratio variation in roe deer (Capreolus capreolus). Behavioral Ecology and Sociobiology 45:339-348.

Hewison, A. J. M., J. M. Gaillard, J. M. Angibault, G. V. Laere, and J. P. Vincent, 2002. The influence of density on post-weaning growth in roe deer Capreolus capreolus fawns. Journal of zoology 257:303-309.

Hewison, A. J. M., J.-M. Gaillard, D. Delorme, G. Van Laere, T. Amblard, and F. Klein, 2011. Reproductive constraints, not environmental conditions, shape the ontogeny of sex-specific mass-size allometry in roe deer. Oikos 120:1217-1226.

Ims, R. A., 1990. On the adaptive value of reproductive synchrony as a predator-swamping strategy. The American Naturalist 136:485-498. 
Jullien, J.-M., D. Delorme, and J.-M. Gaillard, 1992. Détermination de l'âge chez le faon de chevreuil (Capreolus capreolus) dans son premier mois de vie. Mammalia 56:307-311.

Klein, D. R., 1965. Ecology of deer range in Alaska. Ecological Monographs 35:259-284.

Kruuk, L. E. B., T. H. Clutton-Brock, K. E. Rose, and F. E. Guinness, 1999. Early determinants of lifetime reproductive success differ between the sexes in red deer. Proceedings of the Royal Society B: Biological Sciences 266:1655-1661.

Landete-Castillejos, T., A. Garcia, and L. Gallego, 2001. Calf growth in captive Iberian red deer (Cervus elaphus hispanicus): effects of birth date and hind milk production and composition. Journal of Animal Science 79:1085-1092.

Lent, P. C., 1974. Mother-infant relationships in ungulates. In V. Geist and F. R. Walther, editors, The behaviour of ungulates and its relation to management, pages 14-55. IUCN New Series, Morges, Switzerland.

Lindström, J., 1999. Early development and fitness in birds and mammals. Trends in Ecology \& Evolution 14:343-348.

Lummaa, V. and T. H. Clutton-Brock, 2002. Early development, survival and reproduction in humans. Trends in Ecology \& Evolution 17:141-147.

Maciejewski, W., 2014. Reproductive value in graph-structured populations. Journal of Theoretical Biology 340:285-293.

McNamara, J. M. and A. I. Houston, 1996. State-dependent life histories. Nature 380:215-221.

Moorad, J. A., 2014. Individual fitness and phenotypic selection in age-structured populations with constant growth rates. Ecology 95:1087-1095. 
Moyes, K., D. H. Nussey, M. N. Clements, F. E. Guinness, A. Morris, S. Morris, J. M.

Pemberton, L. E. B. Kruuk, and T. H. Clutton-Brock, 2011. Advancing breeding phenology in response to environmental change in a wild red deer population. Global Change Biology $17: 2455-2469$.

Newton, I., 1989. Lifetime reproduction in birds. Academic Press, London.

Nilsen, E. B., J.-M. Gaillard, R. Andersen, J. Odden, D. Delorme, G. Van Laere, and J. D. C. Linnell, 2009. A slow life in hell or a fast life in heaven: demographic analyses of contrasting roe deer populations. Journal of Animal Ecology 78:585-594.

Nussey, D. H., E. Postma, P. Gienapp, and M. E. Visser, 2005. Selection on heritable phenotypic plasticity in a wild bird population. Science 310:304-306.

Pettorelli, N., J.-M. Gaillard, A. Mysterud, P. Duncan, N. C. Stenseth, D. Delorme, G. Van Laere, C. Toïgo, and F. Klein, 2006. Using a proxy of plant productivity (NDVI) to find key periods for animal performance: the case of roe deer. Oikos 112:565-572.

Pettorelli, N., J.-M. Gaillard, G. Van Laere, P. Duncan, P. Kjellander, O. Liberg, D. Delorme, and D. Maillard, 2002. Variations in adult body mass in roe deer: the effects of population density at birth and of habitat quality. Proceedings of the Royal Society B: Biological Sciences 269:747-753.

Plard, F., J.-M. Gaillard, C. Bonenfant, A. J. M. Hewison, D. Delorme, B. Cargnelutti, P. Kjellander, E. B. Nilsen, and T. Coulson, 2013. Parturition date for a given female is highly repeatable within five roe deer populations. Biology letters 9:20120841.

Plard, F., J.-M. Gaillard, T. Coulson, A. J. M. Hewison, D. Delorme, and C. Bonenfant, 2014a. Mismatch between birth date and vegetation phenology slows the demography of roe deer. Plos Biology 12:e1001828. 
Plard, F., J.-M. Gaillard, T. Coulson, A. J. M. Hewison, D. Delorme, E. B. Nilsen, and

C. Bonenfant, 2014b. Long-lived and heavier females give birth earlier in roe deer. Ecography 37:241-249.

Post, E. and M. C. Forchhammer, 2008. Climate change reduces reproductive success of an Arctic herbivore through trophic mismatch. Philosophical Transactions of the Royal Society of London B Biological Sciences 363:2367-2373.

Price, T., M. Kirkpatrick, and S. J. Arnold, 1988. Directional selection and the evolution of breeding date in birds. Science 240:798-799.

Réale, D., D. Berteaux, A. G. McAdam, and S. Boutin, 2003. Lifetime selection on heritable life-history traits in a natural population of red squirrels. Evolution 57:2416-2423.

Reed, T. E., R. S. Waples, D. E. Schindler, J. J. Hard, and M. T. Kinnison, 2010. Phenotypic plasticity and population viability: the importance of environmental predictability. Proceedings of the Royal Society B: Biological Sciences 277:3391-3400.

Reznick, D., E. Schultz, S. Morey, and D. Roff, 2006. On the virtue of being the first born: the influence of date of birth on fitness in the mosquitofish, Gambusia affinis. Oikos 114:135-147.

Rödel, H. G., D. von Holst, and C. Kraus, 2009. Family legacies: short- and long-term fitness consequences of early-life conditions in female European rabbits. Journal of Animal Ecology 78:789-797.

Rutberg, A. T., 1987. Adaptive hypotheses of birth synchrony in ruminants: an interspecific test. The American Naturalist 130:692-710.

Saino, N., M. Romano, R. Ambrosini, D. Rubolini, G. Boncoraglio, M. Caprioli, and A. Romano, 2012. Longevity and lifetime reproductive success of barn swallow offspring are 
predicted by their hatching date and phenotypic quality. Journal of Animal Ecology 81:1004-1012.

Schultz, E., 1993. The effect of birth date on fitness of female dwarf perch, Micrometus minimetus (Perciformes: Embiotocidae). Evolution 47:520-539.

Sheldon, B. C., L. E. B. Kruuk, and J. Merilä, 2003. Natural selection and inheritance of breeding time and clutch size in the collared flycatcher. Evolution 57:406-420.

Shipley, B., 2009. Confirmatory path analysis in a generalized multilevel contextsinervo. Ecology 90:363-368.

Sinervo, B. and P. Doughty, 1996. Interactive effects of offspring size and timing of reproduction on offspring reproduction: experimental, maternal, and quantitative genetic aspects. Evolution 50:1314-1327.

Solberg, E. J., M. Heim, V. Grøtan, B.-E. Sæther, and M. Garel, 2007. Annual variation in maternal age and calving date generate cohort effects in moose (Alces alces) body mass. Oecologia 154:259-271.

Spear, L. and N. Nur, 1994. Brood size, hatching order and hatching date: effects on four life-history stages from hatching to recruitment in western gulls. Journal of Animal Ecology 63:283-298.

Spiegelhalter, D. J., N. G. Best, B. P. Carlin, and A. van der Linde, 2002. Bayesian measures of model complexity and fit. Journal of the Royal Statistical Society. Series B (Statistical Methodology) 64:583-639.

Strandgaard, H., 1972. An investigation of corpora lutea, embryonic development, and time of birth of roe deer (Capreolus capreolus) in Denmark. Vildtbiologisk Station. 
Sydeman, W. J. and J. O. Eddy, 1995. Repeatability in laying date and its relationship to 2 individual quality for common murres. The Condor 97:1048-1052.

Tuljapurkar, S., U. K. Steiner, and S. H. Orzack, 2009. Dynamics heterogeneity in life histories. Ecology letters 12:93-106.

Van de Pol, M., L. Bruinzeel, D. Heg, H. Van der Jeugd, and S. Verhulst, 2006. A silver spoon for a golden future: long-term effects of natal origin on fitness prospects of oystercatchers (Haematopus ostralegus). Journal of Animal Ecology 75:616-626.

Visser, M. E. and N. Verboven, 1999. Long-term fitness effects of fledging date in great tits. Oikos 85:445-450.

Wauters, L. A. and A. A. Dhondt, 1995. Lifetime reproductive success and its correlates in female eurasian squirrels. Oikos 72:402-410.

Wilson, A. J. and D. H. Nussey, 2010. What is individual quality? An evolutionary perspective. Trends in Ecology \& Evolution 25:207-214.

Wilson, A. J., J. G. Pilkington, J. M. Pemberton, D. W. Coltman, A. D. J. Overall, K. A. Byrne, and L. E. B. Kruuk, 2005. Selection on mothers and offspring: whose phenotype is it and does it matter? Evolution 59:451-463. 


\section{Appendix A}

3 Description of the model describing the early life stage and adult stage traits in roe deer

4 including the parameter estimates of the different models, the plots of the survival and the

5 inheritance function for birth date and, the diagnostic plots of the different models.

\section{Appendix B}

Description of the different functions and of the matrix used to build the IPM. R script used to build the IPM.

\section{Supplement}

\section{Appendix C}

Description of the outputs (stable birth date and body mass distributions and, reproductive values) of the IPM. 
Table 1. Model selection for the early life stage and adult stage traits. A. Early survival

(Recruitment function of the IPM). Influence of maternal body mass $\left(B M_{M}\right)$ and individual birth date $\left(B D\right.$, with a threshold date on May $\left.12^{\text {th }}\right)$ on individual early survival (to 8 months of age). B. Yearling body mass (Inheritance function for body mass). Influence of individual birth date $(B D)$ and of maternal body mass $\left(B M_{M}\right)$ on individual yearling body mass. An effect of sex was included in the models because yearling males are heavier than yearling females. C. Yearling survival. Influence of individual birth date $(B D)$ and yearling body mass $\left(B M_{Y}\right)$ on individual yearling survival $(Y)$. D. Adult body mass (Growth). Influence of individual birth date $(B D)$ and yearling body mass $\left(B M_{Y}\right)$ on female adult body mass. An indirect effect of birth date on adult body mass through its effect on yearling body mass was also included in all models using a path analysis. E. Adult survival. Influence of individual birth date $(B D)$ and adult body mass $\left(B M_{A d}\right)$ on female adult survival. $k$ indicates the number of estimated parameters, LL is the maximum log likelihood, Dev is the deviance of the model, $\triangle \mathrm{AIC}$ indicates the difference in the AIC between two competing models, and wi corresponds to Akaike weights. $P d$ is the estimated number of parameters, $\hat{D}$ is the deviance of the model and $\triangle \mathrm{DIC}$ indicates the difference in the DIC between two competing models. The selected models are indicated in bold. 1 represents the constant model (i.e. intercept only). 


\section{TABLE 1.}

\section{Early life stage traits}

\begin{tabular}{lcccc} 
A. early survival & $k$ & $\mathrm{LL}$ & $\Delta \mathrm{AIC}$ & $w i$ \\
\hline $\boldsymbol{B} \boldsymbol{M}_{\boldsymbol{M}}+\boldsymbol{B D}$ & $\mathbf{5}$ & $\mathbf{- 1 8 1 . 3 4 7}$ & $\mathbf{0}$ & $\mathbf{0 . 6 7 3}$ \\
$B D$ & 4 & -185.941 & 7.187 & 0.018 \\
$B M_{M}$ & 4 & -183.140 & 1.585 & 0.304 \\
1 & 3 & -188.334 & 9.975 & 0.005
\end{tabular}

\begin{tabular}{lcccc} 
B. yearling body mass & $k$ & LL & $\Delta$ AIC & $w i$ \\
\hline sex $+\boldsymbol{B} \boldsymbol{M}_{\boldsymbol{M}}+\boldsymbol{B D}$ & $\mathbf{7}$ & $\mathbf{- 2 3 8 . 0 9 1}$ & $\mathbf{0}$ & $\mathbf{0 . 9 7 0}$ \\
sex $+B D$ & 6 & -242.601 & 7.021 & 0.029 \\
se $x+B M_{M}$ & 6 & -246.0224 & 13.863 & 0.001 \\
sex & 5 & -250.932 & 21.682 & $\leq 0.001$ \\
& & & & \\
C. yearling survival & $k$ & $\mathrm{LL}$ & $\Delta \mathrm{AIC}$ & $w i$ \\
\hline$B M_{Y}+B D$ & 4 & -20.757 & 0.488 & 0.345 \\
$\boldsymbol{B} \boldsymbol{M}_{\boldsymbol{Y}}$ & $\mathbf{3}$ & $\mathbf{- 2 1 . 5 1 3}$ & $\mathbf{0}$ & $\mathbf{0 . 4 4 1}$ \\
$B D$ & 3 & -22.875 & 2.724 & 0.113 \\
1 & 2 & -23.980 & 2.934 & 0.102 \\
& & & &
\end{tabular}

\section{Adult stage traits}

\begin{tabular}{lcccc} 
D. adult body mass & $P d$ & $\hat{\mathrm{D}}$ & $\Delta \mathrm{DIC}$ & \\
\hline $\boldsymbol{B} \boldsymbol{M}_{\boldsymbol{Y}}+\boldsymbol{B D}$ & $\mathbf{7}$ & $\mathbf{5 3 7 . 4 0 0}$ & $\mathbf{0}$ & \\
$B M_{Y}$ & 6 & 540.900 & 1.400 & \\
$B D$ & 6 & 580.300 & 40.600 & \\
1 & 5 & 585.300 & 43.500 & \\
& & & & \\
$\mathbf{E .}$ adult survival & $k$ & $\mathrm{Dev}$ & $\Delta \mathrm{AIC}$ & $w i$ \\
\hline$B M_{A d}+B D$ & 7 & 1462.309 & 3.733 & 0.080 \\
$B M_{A d}$ & 6 & 1462.531 & 2.055 & 0.185 \\
$B D$ & 6 & 1462.323 & 1.746 & 0.216 \\
$\mathbf{1}$ & $\mathbf{5}$ & $\mathbf{1 4 6 2 . 5 7 6}$ & $\mathbf{0}$ & $\mathbf{0 . 5 1 8}$ \\
& & & & \\
\hline
\end{tabular}




\section{FigURE CAPTION}

Figure 1. Conceptual model of the relationships among life history traits used to build the five functions of the IPM: the inheritance function for birth date, the inheritance function for body mass, the recruitment, the growth and the survival functions. Dotted arrows indicate potential effects that were not supported by the selected model.

Figure 2. Influence of individual birth date on individual early survival (A.) and yearling body mass (B.) for roe deer at Trois Fontaines, France. (A.) Data used to fit the model are represented by filled circles whose size is proportional to the number of observed births within 25 classes of birth date (of 2 days from April $17^{\text {th }}$ to June $5^{\text {th }}$ ). Males and females were pooled in this analysis (B.) Partial residuals of observed yearling body mass (corrected for maternal body mass and sex) are presented. Males and females are presented in black and grey, respectively, with one point representing one individual. The predictions of the model with their $95 \%$ confidence intervals are presented with a grey shade .

Figure 3. Long-term direct and indirect (i.e. mediated through body mass) influence of individual birth date on individual adult body mass for female roe deer at Trois Fontaines, France. The dotted line gives the predictions of the direct effect of birth date, only.

Figure 4. Percentage change of the difference in fitness between early- and late-born female roe deer generated by a $1 \%$ change in the slopes of each function (Rec: Recruitment, Inh_bd: Inheritance for birth date, Inh_bm: Inheritance for body mass, Gro: Growth and Sur:survival). Perturbations of slopes linking birth date and body mass to the early and adult life history traits are presented in black and white, respectively. 


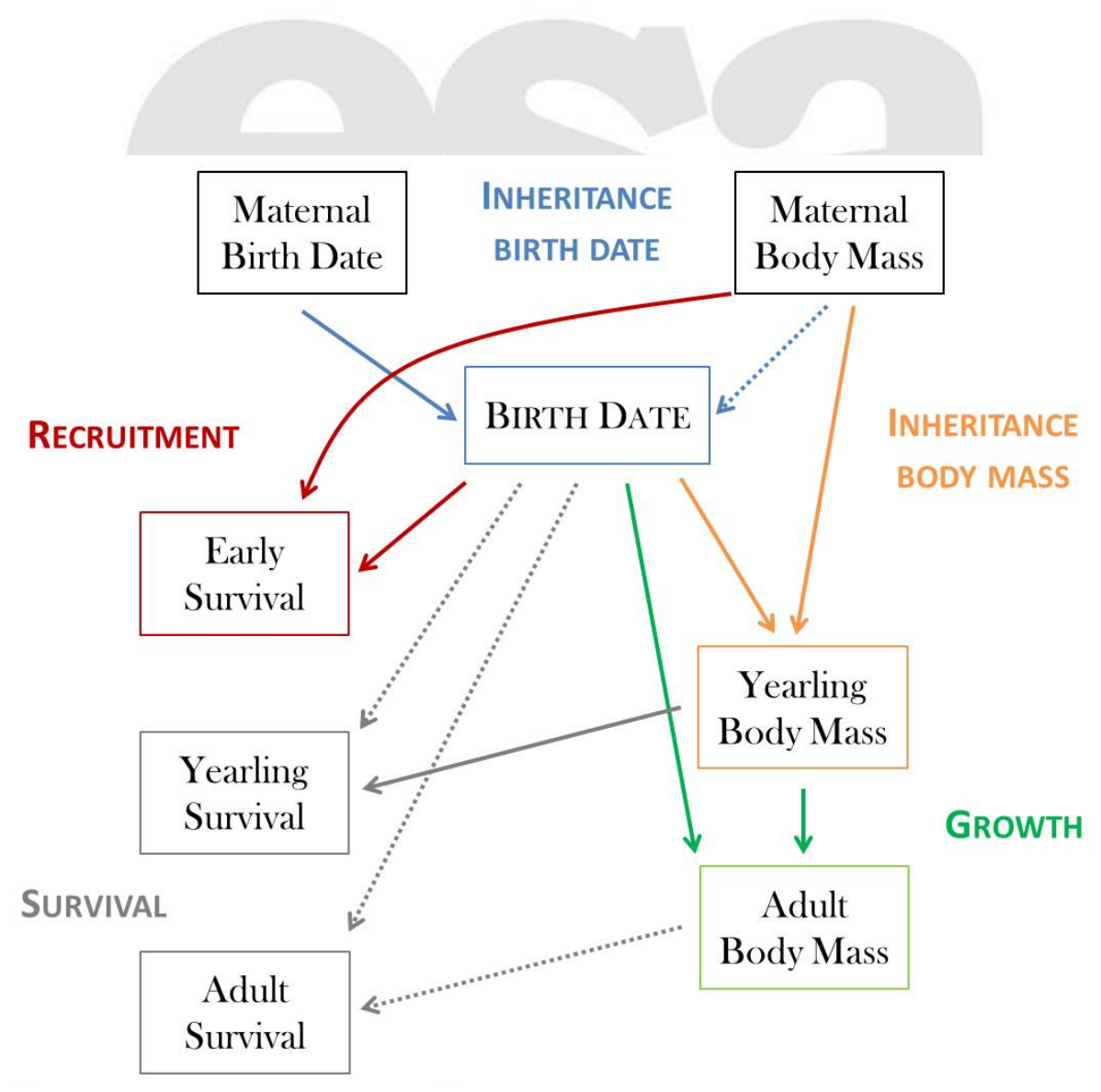

Fig. 1 

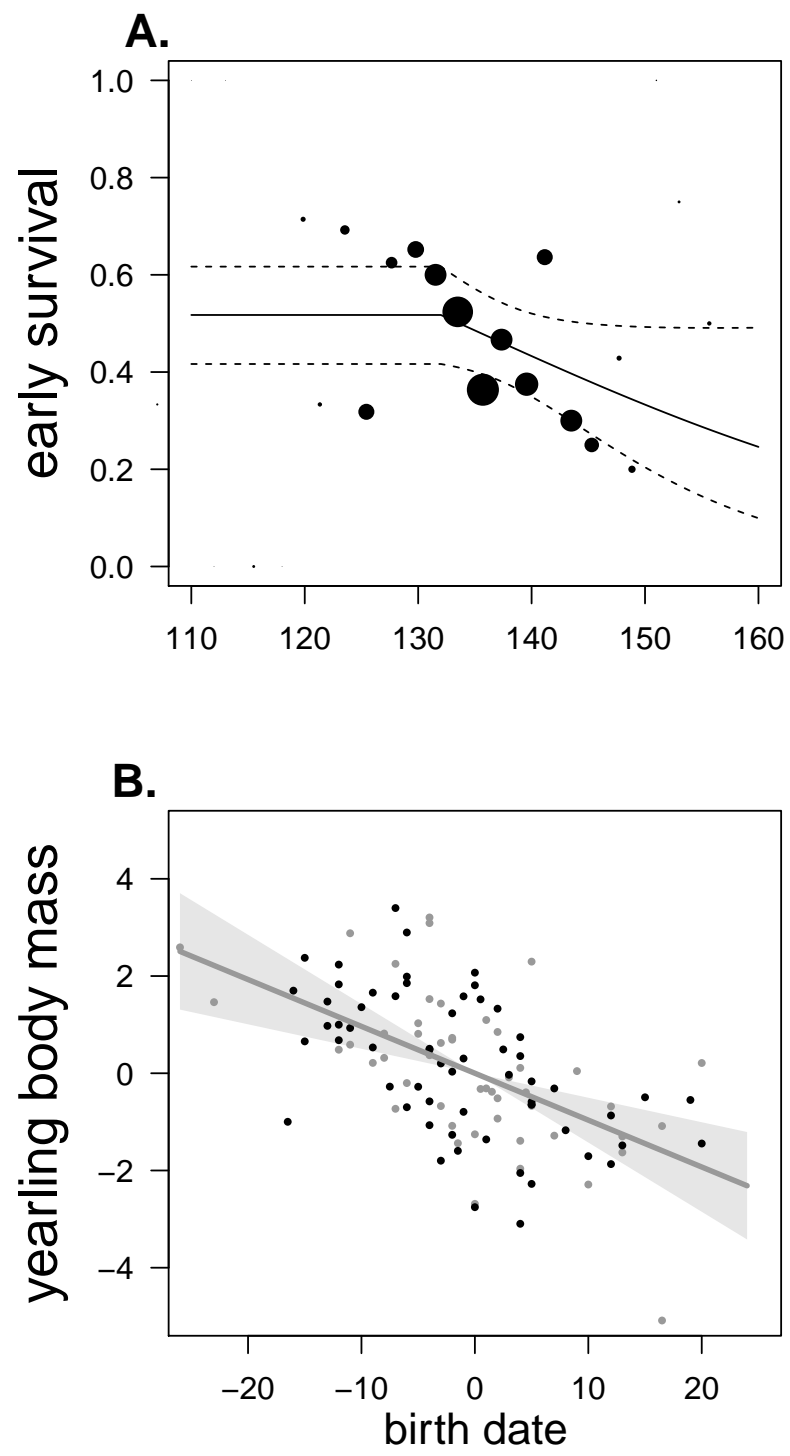

Fig. 2 


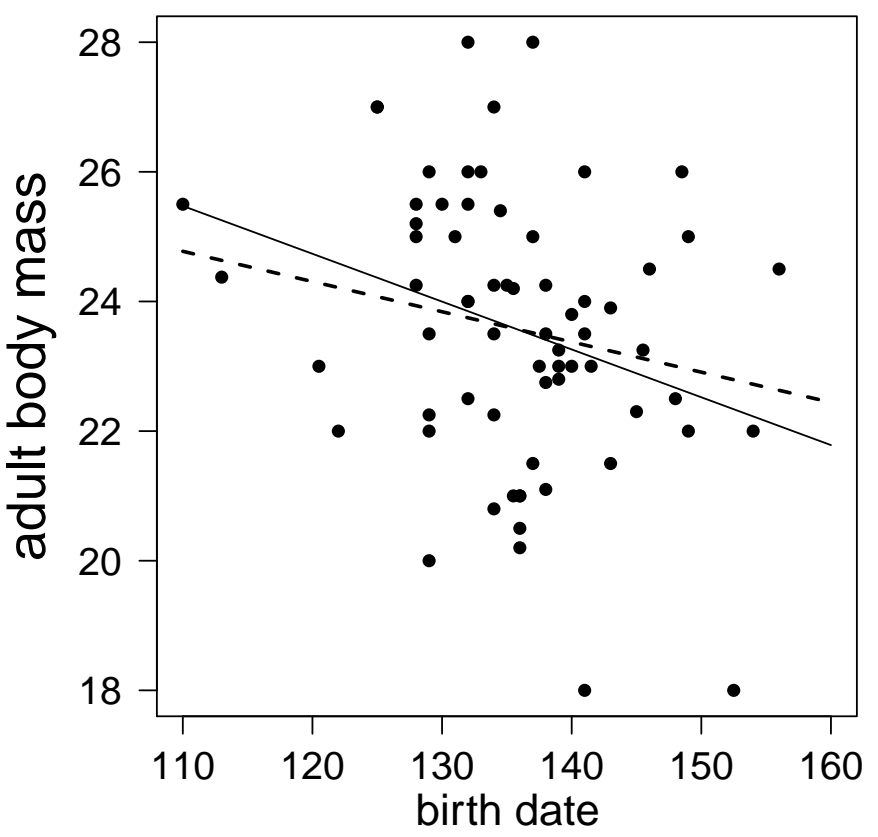

Fig. 3 


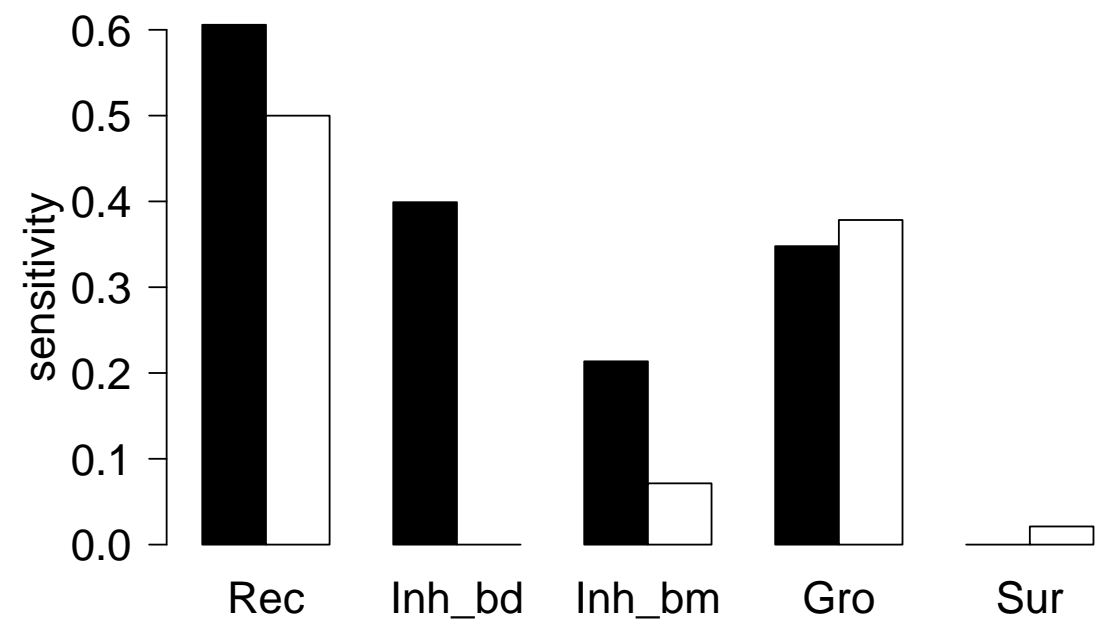

Fig. 4 